\title{
Glycemic control and diabetes management in hospitalized patients in Brazil
}

\author{
Edson Duarte Moreira Jr ${ }^{1,2,3^{*}}$, Patricia Carvalho Balthazar Silveira' ${ }^{1}$, Raimundo Celestino Silva Neves ${ }^{1,3}$, \\ Clodoaldo Souza $\mathrm{Jr}^{1}$, Zaira Onofre Nunes ${ }^{3}$, Maria da Conceição C Almeida ${ }^{3}$ and for the Brazilian Diabetes \\ Investigators' Group
}

\begin{abstract}
Background: The importance of tight blood glucose control among outpatients with diabetes mellitus is well established, however, the management of diabetes in the hospital setting is generally considered secondary in importance. This study sought to assess glycemic control and diabetes management in adult patients admitted to hospitals in Brazil.

Methods: A cross-sectional and nationwide survey was conducted from July 2010 to January 2012. Eligible cases were 18 years of age or older, had a diagnosis of diabetes and a hospitalization length of stay $\geq 72$ hours. Sociodemographic information, hospitalization details, and data on diabetes diagnosis, management and treatment were collected for all patients by chart review. Information on all blood glucose (BG) readings for a maximum of 20 consecutive days of hospitalization was recorded for each patient.

Results: Overall, 2,399 patients were surveyed in 24 hospitals located in 13 cities from all five Brazilian regions. The prevalence of patients presenting hyperglycemic (BG $>180 \mathrm{mg} / \mathrm{dL}$ ) or hypoglycemic (BG $<70 \mathrm{mg} / \mathrm{dL}$ ) events was $89.4 \%$ and $30.9 \%$ in patients in general wards, and $88.2 \%$ and $27.7 \%$ in those in Intensive Care Units (ICUs), respectively. In addition, a BG measure $>180 \mathrm{mg} / \mathrm{dL}$ was recorded in two-thirds of the patient-days. A high proportion of patients were treated with sliding-scale insulin regimen alone in the general wards (52.0\%) and in the ICUs (69.2\%), and only 35.7\% and 3.9\% received appropriate insulin therapy in general wards (basal + bolus insulin) and in ICUs (continuous IV insulin), respectively.

Conclusions: Inpatient glycemic control and diabetes management needs improvement. Opportunities to improve care in Brazilian hospitals include expanded use of intravenous insulin and subcutaneous basal-bolus insulin protocols, avoiding use of sliding-scale insulin alone, increased frequency of blood glucose monitoring, and institution wide quality improvement efforts targeting both physician and nursing behavior.
\end{abstract}

Keywords: Glycemic control, Inpatients, Hospitals, Diabetes mellitus, Epidemiology, Brazil

\section{Background}

The importance of tight blood glucose control among outpatients with type 1 and 2 diabetes mellitus is well established [1,2]. Over the past years, there has been increased attention to inpatient glycemic control, as evidenced by numerous reports published in the medical community [3-5]. Compelling evidence continues

\footnotetext{
* Correspondence: edson@bahia.fiocruz.br

${ }^{1}$ Clinical Research Center, Charitable Works Foundation of Sister Dulce, Av. Bonfim 161, Salvador, Bahia, Brasil 40.415-000

${ }^{2}$ Division of Cancer Epidemiology, McGill University, 546, Pine Avenue West, Montreal, Quebec, Canada H2W 1S6

Full list of author information is available at the end of the article
}

to accumulate suggesting that poorly controlled blood glucose levels among inpatients are associated with increased morbidity and mortality, as well as with higher health care costs [6-9]. In the past decade, studies have focused attention to the possibility that hyperglycemia in the hospital is not necessarily a benign condition and that aggressive treatment of diabetes and hyperglycemia may result in reduced mortality and morbidity [10-12]. In fact, hyperglycemia is a strong predictor of adverse clinical outcome in a range of diseases such as acute stroke $[13,14]$, congestive heart failure $[15,16]$, community acquired pneumonia [17], acute myocardial 
infarction $[18,19]$ and postoperative nosocomial infection [20].

Based upon these findings, the American College of Endocrinology (ACE) and the American Diabetes Association (ADA) have published guidelines recommending tight glucose control for inpatients with diabetes [21,22]. They also recommended the use of continuous insulin infusion given through a standardized protocol as the approach to control hyperglycemia in critically ill inpatients. For noncritical ill diabetic inpatients, they suggested the use of specific insulin regimens with combined basal and short-acting insulin and appropriate bedside glucose monitoring, avoiding the use of sliding-scale insulin (fast or rapid-acting insulin in response to hyperglycemia) alone. More recently, studies showing that intensive glucose control for critically ill patients is associated with severe hypoglycemia and/or increased mortality $[4,5,23]$ have led to less stringent recommendations [7,24-26]. Research assessing inpatient glycemic control state after the development of these guidelines has shown that control is still poor and needs improvement $[3,27,28]$.

The Brazilian Diabetes Society has endorsed the AACE/ ADA recommendations on inpatient glucose control [29], but information about the epidemiology of diabetes and glycemic control in Brazil is scarce. According to a study performed by the Brazilian Ministry of Health in 1992 [30], diabetes was the fifth most common reason for hospitalizations and ranked among the ten major causes of mortality. Moreover, in a large multicenter survey in Brazil, the prevalence of inadequate glycemic control of outpatients with type 1 or type 2 diabetes was $90 \%$ and $73 \%$, respectively [31]. Thus, outpatient diabetes management is a major problem in Brazil, with an impact on public heath comparable to that in other countries worldwide [32-35]. Knowledge on current state of inpatient glycemic control in Brazil is essential for planning healthcare programs targeting improved diabetes control. The purpose of this study was to describe glycemic control and diabetes management in hospitalized patients in Brazil.

\section{Methods}

This cross-sectional and nationwide survey was conducted in Brazil from July 2010 to January 2012. It was designed to portray glycemic control and diabetes management in a sample of adult patients admitted to hospitals in Brazilian urban areas. Study design and reporting format are in accordance with the recommended STROBE (Strengthening the Reporting of Observational Studies in Epidemiology) guidelines [36].

\section{Site selection}

Patients were surveyed in hospitals located in 13 cities belonging to all five Brazilian regions, as follows: Southeast
(Belo Horizonte, Botucatu, Marilia, Rio de Janeiro and São Paulo), South (Campina Grande do Sul, Caxias do Sul, Curitiba, Porto Alegre), Mid-west (Brasília), Northeast (Salvador and Fortaleza) and North (Belém). For the site selection, we identified in each of the participating cities a list of candidate hospitals, to be chosen from those with longer experience in clinical research and epidemiological surveys. Each participating medical center had to be a general hospital, medium to large size ( $>50$ beds), with registry of primary and secondary diagnosis for all inpatients (preferably in an electronic database), and had to have medical chart archives accessible to study data collectors in order to gather information from patient charts. According to these criteria, 30 hospitals were invited to participate in the study. Twenty four accepted and six declined for administrative reasons. Hospitals joining the study were classified as academic (7), public (6), or private (11).

\section{Study population}

Patients who met the eligibility criteria were consecutively included in the study in reverse chronological order proceeding back in time until the target number of patients per site was reached. Eligible patients had to be $\geq 18$ years of age, have a known diagnosis of diabetes (type 1 or type 2) either prior to admission or during the hospitalization, and have a 72-hour or longer length of stay in the hospital. Patients who had been admitted for diabetic ketoacidosis, hyperosmolar hyperglycemic state or gestational diabetes, who had a history of pancreatic transplant, or patients on hospice or palliative care during hospital admission were not included. Each hospital was asked to enroll at least 80 and no more than 120 patients. The study protocol was approved by Ethical Review Boards in each respective city.

\section{Data collection}

Socio-demographic information, hospitalization details, and data on diabetes diagnosis, management and treatment (type and route of insulin administration) were collected for all patients by chart review using a structured questionnaire. Information on all blood glucose (BG) readings for a maximum of 20 consecutive days of hospitalization was recorded for each patient. Measurement day 1 was defined as the day of admission for cases with previously known diabetes or as the day of diagnosis for patients diagnosed with diabetes during the hospitalization. Glucose measurements were recorded for each measurement day as available, both bedside (capillary blood glucose) and laboratory serum glucose values were utilized. Appropriate insulin therapy was defined as scheduled subcutaneous insulin that delivers basal, nutritional, and correction (supplemental) components for non-critically ill patients and as continuous 
intravenous insulin for critically ill patients. Glycosylated hemoglobin (A1C) values were included if they were recorded during the first week of hospitalization or within 30 days prior to admission. A team of study nurses (not part of the hospital staff) was hired and trained for the data collection by one of the investigators (EDM) at each study site. They were given orientation on the protocol and specific details concerning data abstraction, and received technical and content support during the study by the study staff. In addition, a hospital questionnaire was also completed at each site, collecting information on whether the blood glucose measures and insulin administration were recorded in the same form, existence of a protocol for the treatment of hypoglycemia, existence of a mandatory protocol of intravenous insulin infusion for intensive care unit (ICU) patients, and whether the hospital had endocrinology/diabetes team and/or ward.

\section{Statistical analysis}

We employed two analytic approaches for reporting BG levels. One approach, the patient-day approach, grouped BG levels by calendar day for each patient, and then calculated a mean BG level for each patient-day. The other one, the patient approach, employed each patient's mean BG level for the entire hospitalization as a single data point. For each of these approaches, some of the following performance measures were calculated: mean BG level, median BG level and the percentage of BG levels that fell within a predefined "optimal" range (80-139 $\mathrm{mg} / \mathrm{dL}$ ), stratified by location (general ward or ICU). Hypoglycemic (BG $<70 \mathrm{mg} / \mathrm{dL}$ ) and hyperglycemic (BG $>180,>200$ or $>300 \mathrm{mg} / \mathrm{dL}$ ) event rates were also determined. Statistical analyses were performed with Stata version 10 (Stata Corporation, College Station, TX).

\section{Results}

A total of 2,399 patients was surveyed in 24 hospitals (11 private, 7 academic and 6 public) located in 13 cities from all five regions in Brazil. Our sample was comprised by a higher proportion of males than females. The age distribution was skewed towards the older categories, as nearly two-thirds of the subjects were age 60 years or older (Table 1). The Southeast and South regions contributed more patients to the study, while the North and Mid-west regions contributed fewer patients, resembling the demographic distribution of population in Brazil. Most patients had diabetes type 2 and the information on diabetes type was missing in over one third of the patients. Diabetes had been diagnosed prior to admission in nearly all patients (98.7\%). In regard to preadmission diabetes medication regimen, oral antidiabetic drugs were the most common treatment reported (37.7\%), followed by insulin alone (17.3\%), and approximately one-
Table 1 Selected characteristics (\%) of 2,399 hospitalized patients with diabetes in Brazil, 2010-2012

\begin{tabular}{ccc}
\multicolumn{2}{c}{ Location } & Total \\
\cline { 1 - 2 } $\begin{array}{c}\text { General } \\
\text { ward }\end{array}$ & $\begin{array}{c}\text { Intensive } \\
\text { care unit }\end{array}$ & \\
$(n=1,934)$ & $(n=465)$ & $(n=2,399)$
\end{tabular}

Socio demographics

Age in years

$<30$

2.3

0.2

1.9

$30-39$

$40-49$

$50-59$

$60-69$

$\geq 70$

Sex

Male

Female

Region

$\begin{array}{lccc}\text { Male } & 53.7 & 57.2 & 54.4 \\ \text { Female } & 46.3 & 42.8 & 45.6 \\ \text { Region } & & & \\ \text { Southeast } & 46 & 38 & 44 \\ \text { South } & 23 & 11 & 21 \\ \text { Northeast } & 19 & 8 & 17 \\ \text { Midwest } & 8 & 43 & 15 \\ \text { North } & 4 & 0.4 & 3 \\ \text { Hospital type } & & & \\ \text { Private } & 43 & 57 & 46 \\ \text { Academic } & 31 & 27 & 30 \\ \text { Public } & 26 & 16 & 24\end{array}$

Health information

Body mass index $\left(\mathrm{Kg} / \mathrm{m}^{2}\right)$

$\begin{array}{lccc}\text { Underweight }(<18.5) & 2.6 & 0.8 & 2.2 \\ \text { Normal weight }(18.6-24.9) & 31.5 & 24.7 & 30.0 \\ \text { Overweight }(25.0-29.9) & 33.5 & 38.7 & 34.6 \\ \text { Obese }(30.0-39.9) & 29.0 & 31.7 & 29.6 \\ \text { Morbidly obese }(\geq 40.0) & 3.4 & 4.1 & 3.6 \\ \text { Diabetes type } & & & \\ \text { Type 1 } & 9.5 & 3.7 & 8.3 \\ \text { Type 2 } & 55.1 & 62.7 & 56.5 \\ \text { Information not found in the } & 35.4 & 33.6 & 35.2\end{array}$

chart

Preadmission diabetes medication regimen ${ }^{\mathrm{a}}$

$\begin{array}{lccc}\text { None } & 8.9 & 12.8 & 9.6 \\ \text { Oral medications only } & 36.5 & 42.5 & 37.7 \\ \text { Insulin only } & 18.6 & 12.2 & 17.3 \\ \text { Insulin and oral medications } & 11.2 & 7.8 & 10.5 \\ \text { Information not found in the } & 24.8 & 24.7 & 24.9\end{array}$

\section{2}

30.0

34.6

29.6

3.6

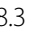

6.5

35.2 
Table 1 Selected characteristics (\%) of 2,399 hospitalized patients with diabetes in Brazil, 2010-2012 (Continued)

\begin{tabular}{lccc}
\hline $\begin{array}{l}\text { Mean hospital length of stay } \\
\text { (days) }\end{array}$ & 14.9 & 13.2 & 14.6 \\
$\begin{array}{l}\text { Median hospital length of } \\
\text { stay (days) }\end{array}$ & 10 & 9 & 10 \\
$\begin{array}{l}\text { Outcome } \\
\quad \text { Discharged }\end{array}$ & 94.2 & 85.5 & 92.6 \\
$\quad$ Transferred & 1.7 & 6.8 & 2.7 \\
$\quad$ Died & 4.1 & 7.7 & 4.8 \\
$\begin{array}{l}\text { Consulted with a diabetes } \\
\text { specialist }\end{array}$ & 12.9 & 3.5 & 11.1 \\
\hline
\end{tabular}

${ }^{a}$ Includes only patients diagnosed with diabetes prior to admission $(n=2,367)$.

${ }^{b}$ Within a 3-day period after hospital admission.

quarter had no information registered on chart. The mean and median hospital lengths of stay were 14.6 and 10 days, respectively. In general, endocrine/diabetes consultation was infrequent, and patients in general wards were more likely to have such consultation than those in ICUs (Table 1).

Hospital performance of recommended diabetes care measures according to location (general ward or ICU) is shown in Table 2. Physician documentation of diabetes history was recorded in more than $95 \%$ of the medical charts, but $16 \%$ or less had an A1C assessment docu-

Table 2 Diabetes management of 2,399 hospitalized patients in Brazil, 2010-2012

\begin{tabular}{|c|c|c|}
\hline & $\begin{array}{c}\text { General } \\
\text { ward } \\
(n=1,934)\end{array}$ & $\begin{array}{c}\text { Intensive } \\
\text { care unit } \\
(n=465)\end{array}$ \\
\hline $\begin{array}{l}\text { Physician documentation of diabetes } \\
\text { history in medical record }\end{array}$ & $95.4^{\mathrm{a}}$ & 97.0 \\
\hline $\begin{array}{l}\mathrm{HbA}_{1 \mathrm{c}} \text { assessment documented for } \\
\text { diabetes patients }^{\mathrm{b}}\end{array}$ & 16.0 & 11.0 \\
\hline $\begin{array}{l}\text { Blood glucose measured within } 8 \text { hours of } \\
\text { admission or diabetes diagnosis }\end{array}$ & 31.2 & 47.1 \\
\hline $\begin{array}{l}\text { Blood glucose monitored at least four } \\
\text { times daily (by patient-days) }\end{array}$ & 55.2 & 61.2 \\
\hline \multicolumn{3}{|l|}{ Diabetes treatment } \\
\hline Sliding-scale insulin only & 52.0 & 69.2 \\
\hline $\begin{array}{l}\text { Short-acting and long-acting subcutaneous } \\
\text { insulin }\end{array}$ & 35.7 & 21.1 \\
\hline $\mathrm{NPH}+$ Bolus & 29.8 & 14.0 \\
\hline Basal+Bolus & 5.9 & 7.1 \\
\hline Continuous IV insulin & 0 & 3.9 \\
\hline Other insulin regimen & 3.6 & 3.5 \\
\hline Oral agents only & 4.8 & 1.3 \\
\hline Diet only & 3.9 & 1.0 \\
\hline
\end{tabular}

apercent.

${ }^{b}$ Measured during first week of hospitalization or within 30 days prior to admission 'Scheduled subcutaneous insulin (basal, nutritional, and correction components). mented. Laboratory glucose assessment within 8 hours of hospital admission for diabetes patients was low in both general wards (31.2\%) and ICUs (47.1\%), and BG monitoring at least 4 times daily occurred in only $55.2 \%$ to $61.2 \%$ of patient-days. A relatively high proportion of patients were treated with sliding-scale insulin regimen alone in the general wards (55.2\%) and in the ICUs (61.2\%), only $35.7 \%$ and $3.9 \%$ received appropriate insulin therapy in general wards and in ICUs, respectively (Table 2).

Measures used to assess the quality of glycemic control in hospitalized patients are presented in Table 3. The percentage of early morning BG readings $\leq 180 \mathrm{mg} / \mathrm{dL}$ on measurement day 3 was not sufficiently high for patients in general wards (54.7\%) and in ICUs (62.8\%). The prevalence of any hyperglycemic (BG >180 $\mathrm{mg} / \mathrm{dL}$ ) or hypoglycemic events (BG <70 mg/dL) was $89.4 \%$ and $30.9 \%$ in patients in general wards, and $88.2 \%$ and $27.7 \%$ in those in ICUs, respectively. In addition, a BG measure $>180 \mathrm{mg} / \mathrm{dL}$ was recorded in about two-thirds of the patient-days, and approximately half of the patient-days had at least one BG value greater than $200 \mathrm{mg} / \mathrm{dL}$. When the threshold was raised to $300 \mathrm{mg} / \mathrm{dL}$, the percentage of any hyperglycemic events ranged from $21.1 \%$ of patientdays in general wards to $16.4 \%$ in ICUs. The percentage of patient-days with any $B G$ value $<70 \mathrm{mg} / \mathrm{dL}$ was relatively low in general wards (6.7\%) and in ICUs (4.9\%). Overall, the percentage of patient-days with BG values within a predefined "optimal" range (80-139 $\mathrm{mg} / \mathrm{dL})$ was only $11.8 \%$ in general wards and $15.0 \%$ in ICUs. The mean percentage of glucose readings $>180 \mathrm{mg} / \mathrm{dL}$ by patient stay (entire hospitalization) was $40.2 \%$ in general wards and $34.9 \%$ in ICUs, while the mean percentage of glucose readings $<70 \mathrm{mg} / \mathrm{dL}$ by patient stay was $2.1 \%$ and $1.6 \%$, respectively. The morning glucose mean by patient-day was $162 \mathrm{mg} / \mathrm{dL}$ in general wards and $158 \mathrm{mg} / \mathrm{dL}$ in ICUs, and the median was $141 \mathrm{mg} / \mathrm{dL}$ and $143 \mathrm{mg} / \mathrm{dL}$, respectively (Table 3).

Characteristics of diabetes management in participating hospitals stratified by type: academic, public or private are shown in Figure 1. All academic hospitals had an endocrinology/diabetes team compared to $71 \%$ and $64 \%$ of public and private hospitals, respectively. A mandatory IV insulin protocol was established at the ICU in most public $(83 \%)$ and private $(82 \%)$ hospitals, while in only $17 \%$ of the ICU in academic hospitals. About half of the hospitals had all point-of-care blood glucose values and insulin doses for a patient listed together on one flow sheet. Similarly, roughly half of the hospitals had an established protocol to treat hypoglycemic events.

\section{Discussion}

To our knowledge, this is the first multicenter, nationwide survey to describe glycemic control and diabetes management in hospitalized patients in Brazil. Overall, 
Table 3 Measures of glycemic control in 2,399 hospitalized patients in Brazil, 2010-2012.

\begin{tabular}{|c|c|c|}
\hline & General ward & Intensive care unit (ICU) \\
\hline Number of patients & 1,934 & 465 \\
\hline$\%$ of $B G$ on morning of $D 3 \leq 180 \mathrm{mg} / \mathrm{dL}$ & 54.7 & 62.8 \\
\hline$\%$ of patients with any $B G>180 \mathrm{mg} / \mathrm{dL}$ & 89.4 & 88.2 \\
\hline$\%$ of patients with any $B G<70 \mathrm{mg} / \mathrm{dL}$ & 30.9 & 27.7 \\
\hline Mean \% glucose readings $>180 \mathrm{mg} / \mathrm{dL}$ analyzed by patient stay (SD) & $40.2(27.6)$ & $34.9(26.1)$ \\
\hline Mean \% glucose readings $<70 \mathrm{mg} / \mathrm{dL}$ analyzed by patient stay (SD) & $2.1(4.5)$ & $1.6(3.3)$ \\
\hline Number of patient-days & 18,887 & 4,227 \\
\hline$\%$ of patient-days with any $B G>180 \mathrm{mg} / \mathrm{dL}$ & 64.7 & 61.3 \\
\hline$\%$ of patient-days with any BG $>200 \mathrm{mg} / \mathrm{dL}$ & 55.8 & 52.1 \\
\hline$\%$ of patient-days with any BG $>300 \mathrm{mg} / \mathrm{dL}$ & 21.1 & 16.4 \\
\hline$\%$ of patient-days with any $B G<70 \mathrm{mg} / \mathrm{dL}$ & 6.7 & 4.9 \\
\hline$\%$ of patient-days with all BG within target range $(80-139 \mathrm{mg} / \mathrm{dL})$ & 11.8 & 15.0 \\
\hline$\%$ of patient-days with mean BG within target range $(80-139 \mathrm{mg} / \mathrm{dL})$ & 30.0 & 32.4 \\
\hline Mean of morning BG analyzed by patient-day (SD) & $162(78)$ & $158(66)$ \\
\hline Median of morning BG analyzed by patient-day & 141 & 143 \\
\hline
\end{tabular}

$\mathrm{BG}=$ fingerstick blood glucose; $\mathrm{D} 3=$ measurement day $3 ; \mathrm{SD}=$ standard deviation.

the quality of inpatient glucose management in hospitals included in our survey was poor. There were several deficiencies in the glycemic control and diabetes management of hospitalized patients in our study. These deficiencies were both in processes of care (e.g., limited use of basal and bolus insulin) and in outcomes (i.e., glycemic control) compared to current recommended guidelines [7,24]. We observed only $11.8 \%-15.0 \%$ of patient-days with mean BG levels between $80-139 \mathrm{mg} / \mathrm{dL}$, though Goldberg et al. [37] have proposed $85 \%$ of patient-days with mean BG levels within this range as a "gold standard" for inpatient glycemic control.

The target of maintaining all glucose values $\leq 180 \mathrm{mg} / \mathrm{dL}$ recommended in the ADA/AACE guidelines for hospital diabetes management was not generally achieved [7,24]. The mean rate of hyperglycemia (BG>180 mg/dL) per patient was higher than previously reported in a survey at a large teaching hospital in the US (40.2\% vs. 31\%) [27].

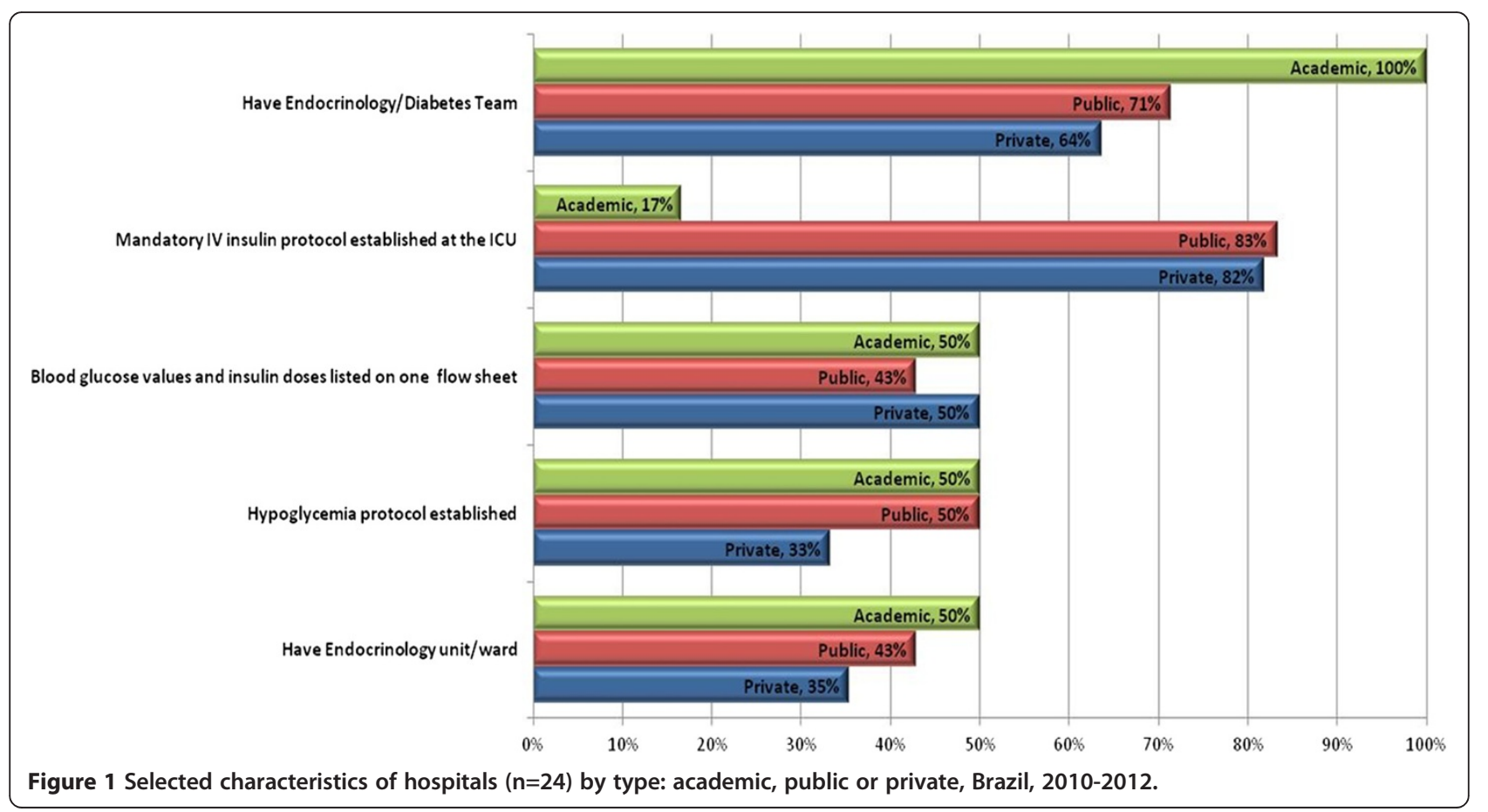


Furthermore, up to two-thirds of patient-days had at least one BG measure above $180 \mathrm{mg} / \mathrm{dL}$. Although hyperglycemia was common, hypoglycemia was relatively infrequent. This should be interpreted with caution, and may be a consequence of insufficient insulin regimens and loose glycemic control rather than an indication of good glycemic management, as suggested by the high rates of hyperglycemia.

Most ICUs in private or public hospitals had a mandatory IV insulin protocol established, as opposed to those in academic hospitals. Nonetheless, overall, very few patients in the ICUs were treated with continuous IV insulin. Thus, suggesting that establishment of an IV insulin protocol is not sufficient and does not guarantee its use will be necessarily mandatory. Failure to provide comprehensive training of ICU personnel about the protocol, lack of appropriate equipment or adequate glucose monitoring, and low awareness regarding the importance of glycemic control are among the potential barriers to implementing a mandatory IV insulin protocol. In addition, more than half of the hospitals in our study had not established a hypoglycemia treatment protocol yet. Poor quality of diabetes care and non-existence of glycemic management guidelines/protocols indicate that there remains potential for substantial improvements in diabetes care in hospitalized patients in Brazil. Formal communication among various professionals and services as well as appropriate training can garner support from health care providers for new practices and protocols.

Appropriate insulin therapy was given to no more than one third of inpatients with diabetes in our study. Basal insulin was prescribed for only $5.9 \%$ of patients, as compared to $43 \%$ for patients in a previous survey [27]. Moreover, most patients with diabetes in our survey received sliding-scale insulin regimen alone, even though it has been shown that sliding-scale insulin by itself is associated with poor inpatient glycemic control and even deleterious effects [38]. In a study of 999 patients with known diabetes treated in 44 hospitals across the U.S., $16 \%$ percent of patients with type 1 diabetes and $35 \%$ of patients with type 2 diabetes (using insulin as outpatients) were treated with sliding-scale insulin alone [39]. Possible barriers to adherence to the recommended standards and optimal diabetes care in our study include a fragmented delivery system, the lack of a system that facilitate the appropriate use of scheduled insulin therapy and low institution support for inpatient multidisciplinary team training.

In regard to performance of recommended hospital diabetes care practices [7,24], there was also evidence for an immediate need for improvement. Few patients had information regarding diabetes type and preadmission medication regimen recorded on their medical charts, and even less patients had an $\mathrm{A} 1 \mathrm{C}$ measurement registered during the first week of hospitalization or within 30 days prior to admission. Thus, indicating poor quality of data recording and the need to improve practices and training of health care personnel. Two-thirds of inpatients with diabetes did not have their blood glucose measured within 8 hours of their hospital admission, and in only $55 \%-61 \%$ of the patient-days the BG was monitored at least four times per day. In contrast, a study conducted on 1,718 patients with a history of diabetes in thirty-seven US academic medical centers found that $31 \%$ had an A1C measurement, $77 \%$ had a laboratory blood glucose result recorded within 8 hours of hospital admission, and $81.3 \%$ had blood glucose monitored at least 4 times on the second day of hospitalization [3].

Insulin-use safety in the hospital setting has recently become a goal to quality improvement efforts [40-42]. Future research should focus on strategies to improve glucose control, as well as on patient, clinician, and system barriers to improving inpatient glycemic management, while enhancing the safe use of insulin in this setting. Factors such as competing priorities and limited resources, skepticism about the benefits of tight inpatient glycemic control, fear of hypoglycemia, inadequate knowledge and understanding of diabetes, hyperglycemia, and appropriate management of blood glucose levels may play an important role in hospital settings similar to ours.

\section{Strengths and limitations}

Strengths of this study include its data collection methods with rigorous inclusion criteria, collection of detailed glycemic data by a team of non-staff trained personnel, and use of various statistical approaches to more accurately assess glycemic control. We also included a large sample of inpatients from private, public and academic hospitals located in all five Brazilian regions. Despite this, there are some limitations to this study. The data are retrospective and only a limited number of clinical variables could be assessed for each patient. There could also have been differences in the frequency of glucose measurement depending on treatment, which can potentially bias estimated prevalence of hyperglycemia and hypoglycemia. We also did not have a practical method to assess nutritional status or the adequacy of insulin dosing over time for each patient.

\section{Conclusions}

Our results indicate that inpatient glycemic control and diabetes management still needs much improvement, despite the evidence of the hazards of inpatient hyperglycemia and the publication of specialist consensus guidelines on inpatient glucose management in the past decade. Opportunities to improve care in Brazilian hospitals include expanded use of intravenous insulin, subcutaneous 
basal insulin and scheduled nutritional insulin protocols, increased frequency of blood glucose monitoring, avoiding use of sliding-scale insulin by itself, and institution wide quality improvement efforts targeting health care personnel behavior.

\section{Appendix}

The following is a list of co-authors, the members of the Brazilian Diabetes Investigators' Group: Adriana C. Forti, MD; Célio C. Borges, MD; Débora V. Soares, MD; Edson P. Brum, MD; Elza M. S. Constantino, MD; Francisco A. Oliveira, MD; Freddy Eliaschewitz, MD; Hermelinda Pedrosa, MD; Jorge Gross, MD; José E. P. Oliveira, MD; Lucia Cordeiro, MD; Lúcia P. E. Souza, MD; Marcia Nery, MD; Marcos Tambascia, MD; Maria R. Calsolari, MD; Reinaldo B. M. Machado, MD; Reine Chaves, MD; Rosane Kupfer, MD; Ruy Lyra, MD; Saulo Cavalcante, MD; and Silmara Leite, MD.

\section{Abbreviations}

BG: Blood glucose; ICU: Intensive care unit; ACE: American college of endocrinology; ADA: American diabetes association; STROBE: Strengthening the reporting of observational studies in epidemiology; A1C: Glycosylated haemoglobin; SD: Standard deviation.

\section{Competing interests}

EDM has received grant support through his institution from Sanofi-Aventis, Merck, Pfizer and Novartis, and was compensated by Sanofi-Aventis, Merck and Pfizer for serving at Scientific Advisory Committee. All other academic co-authors have no disclosure.

\section{Authors' contributions}

EDM conceived the study hypothesis, supervised data analyses and wrote the manuscript, PCBS, ZON and MCCA took a lead role in the data collection. RCSN and CS contributed to the study design and to the data interpretation. PCBS made substantial contribution to data analysis and writing of the manuscript. All authors read and approved the final manuscript.

\section{Acknowledgements}

The authors thank all the healthcare providers and investigators involved with this study. We are indebted to Ana Garcia, Fabio Ikedo, Felipe Pedrosa, Isabel Vergani and Sheila Homsani for their contributions during the development stage of this research. We are especially grateful to Angelo Chiodi and Ana Truzzi for valuables comments on earlier versions of the manuscript, to Tâmara Costa, Juliana Cardoso, Terezinha Ribeiro, Lilian Ribeiro, Débora Santos and Victor Fonseca for helping with logistic support and planning for the field work and data collection. We also appreciate the invaluable administrative and technical assistance of Monica Bortolini.

\section{Funding/Support and role of the sponsor}

This study was funded by a research grant from Sanofi-Aventis, which played a role in and provided support for the study in the following ways: design and conduct of the study, data collection and monitoring, and approval of final version of manuscript. The lead author (EDM) takes responsibility for the integrity of the data and the accuracy of the data analysis. The opinions expressed in this report represent the consensus of the co-authors and do not reflect the formal position of Sanofi-Aventis or the other institutions listed as author affiliations.

\section{Author details}

${ }^{1}$ Clinical Research Center, Charitable Works Foundation of Sister Dulce, Av. Bonfim 161, Salvador, Bahia, Brasil 40.415-000. ${ }^{2}$ Division of Cancer Epidemiology, McGill University, 546, Pine Avenue West, Montreal, Quebec, Canada H2W 156. ${ }^{3}$ Gonçalo Moniz Research Center, Oswaldo Cruz Foundation, Brazilian Ministry of Health, Rua Waldemar Falcão 121, Salvador, Bahia, Brasil, 40.296-710.
Received: 12 July 2013 Accepted: 7 October 2013

Published: 18 October 2013

\section{References}

1. The Diabetes Control and Complications Trial Research Group: The effect of intensive treatment of diabetes on the development and progression of long-term complications in insulin-dependent diabetes mellitus. New England J Med 1993, 329:977-986.

2. UK Prospective Diabetes Study (UKPDS) Group: Intensive blood-glucose control with sulphonylureas or insulin compared with conventional treatment and risk of complications in patients with type 2 diabetes (UKPDS 33). Lancet 1998, 352:837-853.

3. Boord JB, Greevy RA, Braithwaite SS, Arnold PC, Selig PM, Brake H, Cuny J, Baldwin D: Evaluation of hospital glycemic control at US academic medical centers. J Hosp Med 2009, 4:35-44.

4. Finfer S, Chittock DR, Su SY, Blair D, Foster D, Dhingra V, Bellomo R, Cook D, Dodek P, Henderson WR, et al: Intensive versus conventional glucose control in critically ill patients. New England J Med 2009, 360:1283-1297.

5. Wiener RS, Wiener DC, Larson RJ: Benefits and risks of tight glucose control in critically ill adults: a meta-analysis. Jama 2008, 300:933-944.

6. American Diabetes A: Economic costs of diabetes in the U.S. in 2007. Diabet Care 2008, 31:596-615.

7. Moghissi ES, Korytkowski MT, DiNardo M, Einhorn D, Hellman R, Hirsch IB, Inzucchi SE, Ismail-Beigi F, Kirkman MS, Umpierrez GE: American Association of Clinical Endocrinologists and American Diabetes Association consensus statement on inpatient glycemic control. Endocr Pract 2009, 15:353-369.

8. Umpierrez GE, Isaacs SD, Bazargan N, You X, Thaler LM, Kitabchi AE: Hyperglycemia: an independent marker of in-hospital mortality in patients with undiagnosed diabetes. J Clin Endocrinol Metab 2002, 87:978-982

9. Malmberg K, Norhammar A, Wedel H, Ryden L: Glycometabolic state at admission: important risk marker of mortality in conventionally treated patients with diabetes mellitus and acute myocardial infarction: longterm results from the Diabetes and Insulin-Glucose Infusion in Acute Myocardial Infarction (DIGAMI) study. Circulation 1999, 99:2626-2632.

10. van den Berghe $G$, Wouters $P$, Weekers F, Verwaest C, Bruyninckx F, Schetz $M$, Vlasselaers D, Ferdinande P, Lauwers P, Bouillon R: Intensive insulin therapy in critically ill patients. New England J Med 2001, 345:1359-1367.

11. Lazar HL, Chipkin SR, Fitzgerald CA, Bao Y, Cabral H, Apstein CS: Tight glycemic control in diabetic coronary artery bypass graft patients improves perioperative outcomes and decreases recurrent ischemic events. Circulation 2004, 109:1497-1502.

12. Furnary AP, Wu Y, Bookin SO: Effect of hyperglycemia and continuous intravenous insulin infusions on outcomes of cardiac surgical procedures: the Portland diabetic project. Endocr Pract 2004, 10(Suppl 2):21-33.

13. Capes SE, Hunt D, Malmberg K, Pathak P, Gerstein HC: Stress hyperglycemia and prognosis of stroke in nondiabetic and diabetic patients: a systematic overview. Stroke 2001, 32:2426-2432.

14. Jorgensen H, Nakayama H, Raaschou HO, Olsen TS: Stroke in patients with diabetes. The Copenhagen stroke study. Stroke 1994, 25:1977-1984.

15. Guazzi M, Brambilla R, De Vita S, Guazzi MD: Diabetes worsens pulmonary diffusion in heart failure, and insulin counteracts this effect. Am J Respir Crit Care Med 2002, 166:978-982.

16. Masoudi FA, Wang Y, Inzucchi SE, Setaro JF, Havranek EP, Foody JM, Krumholz HM: Metformin and thiazolidinedione use in medicare patients with heart failure. Jama 2003, 290:81-85.

17. McAlister FA, Majumdar SR, Blitz S, Rowe BH, Romney J, Marrie TJ: The relation between hyperglycemia and outcomes in 2,471 patients admitted to the hospital with community-acquired pneumonia. Diabet Care 2005, 28:810-815.

18. Capes SE, Hunt D, Malmberg K, Gerstein HC: Stress hyperglycaemia and increased risk of death after myocardial infarction in patients with and without diabetes: a systematic overview. Lancet 2000, 355:773-778.

19. Malmberg K, Ryden L, Wedel H, Birkeland K, Bootsma A, Dickstein K, Efendic S, Fisher M, Hamsten A, Herlitz J, et al: Intense metabolic control by means of insulin in patients with diabetes mellitus and acute myocardial infarction (DIGAMI 2): effects on mortality and morbidity. Eur Heart $J$ 2005, 26:650-661. 
20. Grey NJ, Perdrizet GA: Reduction of nosocomial infections in the surgical intensive-care unit by strict glycemic control. Endocr Pract 2004, 10(Suppl 2):46-52.

21. Association AD: Standards of medical care in diabetes. Diabet Care 2005, 28:s4-s36.

22. Garber AJ, Moghissi ES, Bransome ED Jr, Clark NG, Clement S, Cobin RH, Furnary AP, Hirsch IB, Levy P, Roberts R, et al: American College of Endocrinology position statement on inpatient diabetes and metabolic control. Endocr Pract 2004, 10(Suppl 2):4-9.

23. Finfer S, Liu B, Chittock DR, Norton R, Myburgh JA, McArthur C, Mitchell Foster D, Dhingra V, Henderson WR, et al: Hypoglycemia and risk of death in critically ill patients. New England J Med 2012, 367:1108-1118.

24. Association AD: Standards of medical care in diabetes-2013. Diabetes Care 2013, 36(Suppl 1):S11-S66

25. Jacobi J, Bircher N, Krinsley J, Agus M, Braithwaite SS, Deutschman C, Freire AX, Geehan D, Kohl B, Nasraway SA, et al: Guidelines for the use of an insulin infusion for the management of hyperglycemia in critically ill patients. Crit Care Med 2012, 40:3251-3276.

26. Qaseem A, Chou R, Humphrey LL, Shekelle P: Inpatient glycemic control: best practice advice from the clinical guidelines committee of the American college of physicians. Am J Med Qual 2013. Available from: http://ajm.sagepub.com/content/early/2013/06/06/1062860613489339. abstract.

27. Schnipper JL, Barsky EE, Shaykevich S, Fitzmaurice G, Pendergrass ML: Inpatient management of diabetes and hyperglycemia among general medicine patients at a large teaching hospital. J Hosp Med 2006, $1: 145-150$.

28. Swanson CM, Potter DJ, Kongable GL, Cook CB: Update on inpatient glycemic control in hospitals in the United States. Endocr Pract 2011, 17:853-861.

29. Sociedade Brasileira de Diabetes. Controle da hiperglicemia intra-hospitalar em pacientes críticos e não críticos. 2011. Available from: http://www.diabetes. org.br/attachments/posicionamento/posicionamento-sbd-n-02-2011.pdf.

30. Malerbi DA, Franco LJ: Multicenter study of the prevalence of diabetes mellitus and impaired glucose tolerance in the urban Brazilian population aged 30-69 yr. The Brazilian cooperative group on the study of diabetes prevalence. Diabet Care 1992, 15:1509-1516.

31. Mendes AB, Fittipaldi JA, Neves RC, Chacra AR, Moreira ED Jr: Prevalence and correlates of inadequate glycaemic control: results from a nationwide survey in 6,671 adults with diabetes in Brazil. Acta diabetologica 2010, 47:137-145.

32. Fox KM, Gerber Pharmd RA, Bolinder B, Chen J, Kumar S: Prevalence of inadequate glycemic control among patients with type 2 diabetes in the United Kingdom general practice research database: a series of retrospective analyses of data from 1998 through 2002. Clin Ther 2006, 28:388-395.

33. Harris SB, Ekoe JM, Zdanowicz Y, Webster-Bogaert S: Glycemic control and morbidity in the Canadian primary care setting (results of the diabetes in Canada evaluation study). Diab Res Clin Pract 2005, 70:90-97.

34. Kobayashi M, Yamazaki K, Hirao K, Oishi M, Kanatsuka A, Yamauchi M, Takagi $\mathrm{H}$, Kawai $\mathrm{K}$ : The status of diabetes control and antidiabetic drug therapy in Japan-a cross-sectional survey of 17,000 patients with diabetes mellitus (JDDM 1). Diab Res Clin Pract 2006, 73:198-204.

35. Moreira ED Jr, Neves RC, Nunes ZO, de Almeida MC, Mendes AB, Fittipaldi JA, Ablan F: Glycemic control and its correlates in patients with diabetes in Venezuela: results from a nationwide survey. Diab Res Clin Pract 2010, 87:407-414

36. von Elm E, Altman DG, Egger M, Pocock SJ, GÃs,tzsche PC, Vandenbroucke JP: The Strengthening the Reporting of Observational Studies in Epidemiology (STROBE) Statement: guidelines for reporting observational studies. Prev Med 2007, 45:247-251.

37. Goldberg PA, Bozzo JE, Thomas PG, Mesmer MM, Sakharova OV, Radford MJ Inzucchi SE: "Glucometrics"-assessing the quality of inpatient glucose management. Diabetes Technol Ther 2006, 8:560-569.

38. Queale WS, Seidler AJ, Brancati FL: Glycemic control and sliding scale insulin use in medical inpatients with diabetes mellitus. Arch Intern Med 1997, 157:545-552

39. Wexler DJ, Meigs JB, Cagliero E, Nathan DM, Grant RW: Prevalence of hyper- and hypoglycemia among inpatients with diabetes: a national survey of 44 U.S. hospitals. Diabetes care 2007, 30:367-369.
40. Cobaugh DJ, Maynard G, Cooper L, Kienle PC, Vigersky R, Childers D, Weber R, Carson SL, Mabrey ME, Roderman N, et al: Enhancing insulin-use safety in hospitals: practical recommendations from an ASHP Foundation expert consensus panel. Am J Health Syst Pharm 2013, 70:1404-1413.

41. Cousins D, Rosario C, Scarpello J: Insulin, hospitals and harm: a review of patient safety incidents reported to the National Patient Safety Agency. Clin Med 2011, 11:28-30.

42. Thomas AN, Panchagnula U: Medication-related patient safety incidents in critical care: a review of reports to the UK national patient safety agency. Anaesthesia 2008, 63:726-733.

doi:10.1186/1758-5996-5-62

Cite this article as: Moreira et al:: Glycemic control and diabetes management in hospitalized patients in Brazil. Diabetology \& Metabolic Syndrome 2013 5:62.

\section{Submit your next manuscript to BioMed Central and take full advantage of:}

- Convenient online submission

- Thorough peer review

- No space constraints or color figure charges

- Immediate publication on acceptance

- Inclusion in PubMed, CAS, Scopus and Google Scholar

- Research which is freely available for redistribution 